\title{
Repercussões do Programa Mais Médicos na mídia brasileira após o Impeachment de 2016
}

\author{
Repercussions of the More Doctors Program in the Brazilian media \\ after the Impeachment of 2016
}

David Ramos da Silva Rios (https://orcid.org/0000-0003-2439-6161) ${ }^{1}$

Susanne Pinheiro Costa e Silva (https://orcid.org/0000-0002-9864-3279) ${ }^{2}$

\footnotetext{
1 Programa de Residência Médica em Medicina da Família e Comunidade, Complexo Hospitalar Universitário Professor Edgard Santos, Universidade Federal da Bahia. R. Barão de Jeremoabo $\mathrm{s} / \mathrm{n}$, Ondina. 40170-115 Salvador BA Brasil. david-rios@hotmail.com ${ }^{2}$ Departamento de Enfermagem em Saúde Coletiva, Centro de Ciências da Saúde, Universidade Federal da Paraíba. João Pessoa PB Brasil.
}

\begin{abstract}
The More Doctors Program (PMM) launched in 2013 has set major changes in the health sector in motion. However, several changes in its operation have been noted in recent years due to a range of social and political events. This article seeks to identify and analyze the repercussions of the PMM in the Brazilian media after the impeachment occurred in 2016. It is an exploratory study based on the analysis of the subject matter gathered from the identification, selection and analysis of news coverage published in three newspapers with widespread circulation throughout Brazil (Jornal O Globo, Folha de São Paulo and Estadão), in the period from August 2016 to June 2018. The data collected were processed using Iramuteq software. The results reveal that the $\mathrm{Cu}$ ban physicians and issues related to medical education and governability of the PMM were at the center of public news attention after the impeachment, with social actors beginning to defend new stances. Thus, although the implementation of the PMM is already well advanced and has popular support, important changes are being made and require thorough evaluation, seeking to guarantee the rights already acquired.
\end{abstract}

Key words Primary Health Care, Health policy, Physicians, Qualified foreign physicians
Resumo O Programa Mais Médicos (PMM), lançado em 2013, desencadeou importantes mudanças no setor saúde. Entretanto, diversas alterações em seu funcionamento vêm sendo notadas nos últimos anos em decorrência de uma gama de eventos sociais e politicos. O presente artigo busca identificar e analisar as repercussões da mídia brasileira acerca do PMM após o "impeachment" ocorrido em 2016. Trata-se de um estudo exploratório, que teve o seu "corpus de análise" constituído a partir da identificação, seleção e análise de notícias publicadas em três jornais de grande circulação nacional (Jornal O Globo, Folha de São Paulo e Estadão), no período de Agosto de 2016 a Junho de 2018. Os dados coletados foram analisados por meio do software "Iramuteq". Os resultados demonstram que os médicos cubanos e temas relacionados à educação médica e à governabilidade do PMM estiveram no cerne das notícias publicadas após o "impeachment", com os atores sociais defendendo novos posicionamentos. Destarte, apesar da implementação do PMM já estar bem avançada e possuir respaldo popular, mudanças importantes estão sendo feitas e requerem avaliação minuciosa, visando à garantia dos direitos já conquistados.

Palavras-chave Atenção primária à saúde, Política de saúde, Médicos, Médicos graduados estrangeiros 


\section{Introdução}

A distribuição desigual de médicos no território brasileiro, bem como a ausência de prestação de assistência à saúde a populações em áreas longínquas aos centros urbanos, são temáticas que requerem atenção desde meados de $1960^{1}$. Uma gama de programas e ações do governo federal brasileiro visando reduzir tais iniquidades, a exemplo do Projeto Rondon, Programa de Interiorização das Ações de Saúde e Saneamento (Piass), Programa de Interiorização do Trabalho em Saúde (Pits), Programa de Valorização do Profissional da Atenção Básica (PROVAB), dentre outros, foram implementados para colaborar com o enfrentamento de tal situação ${ }^{1}$.

A maior parte de tais iniciativas não apresentou resultados significativos, apesar dos esforços envidados, o cotidiano de diversas comunidades em regiões periféricas, no interior dos Estados e principalmente nas Regiões Norte e Nordeste do país, permaneceu marcado pela forte desassistência da atenção médica².

Inúmeras evidências são aventadas para a manutenção dessa realidade: formação médica díspar e distante dos princípios do Sistema Único de Saúde (SUS); corporativismo da categoria; natureza pontual das ações do governo federal; falta de infraestrutura nas regiões interioranas, bem como a ausência de um plano de carreira nacional para os médicos ${ }^{2-5}$.

Dados provenientes do estudo "Demografia Médica", de 2018, realizado pela Faculdade de Medicina da Universidade de São Paulo (FMUSP), com apoio do Conselho Federal de Medicina (CFM) e do Conselho Regional de Medicina do Estado de São Paulo (Cremesp), mostram que há grande concentração de profissionais nas regiões mais desenvolvidas do país, nas capitais e no litoral. A região Sudeste continua sendo aquela com maior razão de médicos por 1.000 habitantes: 2,81 contra 1,16 no Norte e 1,41 no Nordeste. Do total de médicos do país, $28 \%$ estão no estado de São Paulo, com uma razão de 2,81 médicos para cada 1000 habitantes. O Distrito Federal, por sua vez, tem a maior relação médico/habitantes: 4,35/1000, demonstrando uma relação díspar daquela observada em estados como o Maranhão ( 0,87 médico por mil habitantes) e o Pará, com razão de $0,97^{6}$. Ademais, é importante destacar que apesar disso, $94,4 \%$ dos profissionais do Distrito Federal se concentram na capital. Apenas 173 dos 12.649 médicos possuem especialização em Medicina Geral de Família e Comunidade e/ ou Medicina Preventiva e Social, especialidades estas que se relacionam diretamente com a atuação na atenção primária à saúde .

As desigualdades observadas no contingente de médicos a nível nacional não se restringem apenas a esta dimensão, visto que quando comparadas com outros países, com sistema de saúde semelhante ou realidades sociais parecidas à brasileira, a relação de médicos por habitantes no Brasil é significativamente inferior. Apesar da proporção ter crescido nos últimos cinco anos, ela ainda é menor que a de outros países: Brasil, 2,18 médicos/1000 hab., Argentina, 3,2 médicos/1000 hab., Uruguai 3,7 médicos/1000 hab. ${ }^{6,7}$. Esta diferença também é notada na proporção de vagas de ingressos no curso de graduação em medicina para cada 10.000 mil habitantes: Brasil, 0,8; Austrália 1,4; Portugal 1,6; Argentina 3,18.

Aliada ao contexto social e político vivenciado pelo Brasil, em meados de 2013, estas problemáticas foram o mote de diferentes movimentos, a exemplo da campanha "Cadê o médico?", lançada pela Frente Nacional de Prefeitos e as chamadas Jornadas de Junho ${ }^{9}$, influenciadas pela Primavera Árabe ${ }^{10}$. Tais manifestações se propagaram no país e questionavam os investimentos do governo federal com os jogos futebolísticos da Copa do Mundo de 2014, enquanto os cidadãos vivenciavam, cotidianamente, a má qualidade dos serviços públicos?.

Diante da realidade apresentada, da persistência da problemática envolvendo a distribuição dos médicos no território ao longo do tempo, da ineficiência das ações e dos programas elaborados até então, bem como das demandas sociais e políticas vivenciadas em 2013, a então presidente da República, Dilma Rousseff, lançou um conjunto de pactos em favor do Brasil, estruturados em cinco temas prioritários: Economia, Política, Saúde, Educação e Transporte ${ }^{11}$.

$\mathrm{Na}$ Saúde, as ações se concentraram principalmente na criação e na implementação do Programa Mais Médicos (PMM), instituído inicialmente por meio de Medida Provisória em julho de 2013, que posteriormente foi convertida em Lei (No 12.871 de 22 de Outubro de 2013). O PMM foi estruturado em três pilares (provimento emergencial de médicos, educação médica, $\mathrm{e}$ infraestrutura) e representou uma importante inovação ao congregar em uma mesma proposta diferentes ministérios: Saúde, Educação e Planejamento, Orçamento e Gestão ${ }^{12}$.

Embora seja uma importante inovação no contexto brasileiro, programas semelhantes ao PMM não são novidades no cenário mundial. Diferentes países, a exemplo do Canadá, Austrá- 
lia e África do Sul, já possuem experiências com programas voltados ao provimento de médicos e à distribuição equitativa dos profissionais no território ${ }^{13}$.

Dentre os objetivos do PMM estão: diminuir a carência de médicos nas regiões prioritárias para o SUS; fortalece a prestação de serviços na atenção básica; aprimorar a formação médica, com o aumento da quantidade de campos de prática; ampliar a inserção do médico em formação nas unidades de atendimento do SUS; fortalecer a política de educação permanente, com a integração educação-serviço, por meio da supervisão acadêmica; promover a troca de experiências entre os médicos brasileiros e os estrangeiros; estimular pesquisas voltadas ao SUS e aperfeiçoar os médicos para atuação em políticas públicas de saúde ${ }^{12}$.

Para além de medidas que visam resultados a curto prazo, como o provimento de médicos, o PMM também propôs uma gama de estratégias que buscam garantir efeitos a longo prazo, dentre elas estão a indução da abertura e a universalização de vagas de Residência Médica em determinadas especialidades e regiões ${ }^{14}$, com a priorização da expansão dos Programas de Residência em Medicina Geral de Família e Comunidade (MGFC) ${ }^{15-17}$.

Mesmo com a ampliação do número de vagas em MGFC decorrentes do PMM, é necessário destacar que dois problemas se mantêm: a ocupação das vagas ofertadas e a permanência dos médicos residentes nos programas ${ }^{18}$. Além do mais, a obrigatoriedade dos anos iniciais em MGFC para que os médicos estivessem aptos a cursarem outras especialidades sofreu resistência de diferentes categorias. $\mathrm{Na}$ tentativa de se chegar a um consenso, garantiu-se, então, pontuação adicional de $10 \%$ em processo seletivo de residência médica em outra especialidade, para quem concluir a residência em $\mathrm{MGFC}^{18,19}$.

Apesar de pela primeira vez uma ação governamental integrar em um mesmo programa a proposta de redistribuição dos profissionais médicos, a implementação de mudanças no processo de formação médica, bem como a melhoria da infraestrutura das unidades básicas de saúde, o mesmo foi amplamente criticado pela categoria médica e por outros setores sociais, que caracterizavam o PMM como "uma farsa" ${ }^{20}$, elaborado apenas com objetivos políticos, visto que a baixa adesão de profissionais brasileiros a determinados territórios dar-se-ia em decorrência das "péssimas" condições de trabalho na atenção primária do Brasil ${ }^{20}$.
Em meio a disputas e debates entre Governo Federal, entidades médicas e demais associações ligadas ao campo da Saúde, como a Associação Brasileira de Saúde Coletiva (Abrasco) e o Centro Brasileiro de Estudos de Saúde (Cebes), os meios de comunicação impressos, televisivos e online tiveram um exímio papel na produção, transmissão e cobertura de pontos de vista que re(produziam) posições favoráveis ou contrárias em relação ao $\mathrm{PMM}^{21,22}$.

Destarte, inúmeros estudos ${ }^{21-26}$ foram realizados buscando analisar a reação de diversas categorias e atores sociais sobre o PMM em diferentes mídias: jornais e revistas impressas, jornais televisivos, sites de internet e redes sociais. A maior parte deles destacou principalmente as percepções das entidades médicas e seus pontos de discussões: abertura de novas vagas nos cursos de medicina, a vinda de médicos estrangeiros, consequências negativas para o mercado de trabalho, dentre outros aspectos ${ }^{1}$. Os estudos sobre a cobertura da imprensa brasileira acerca do PMM apresentam três elementos principais: $\mathrm{o}$ viés político, a polarização das opinióes veiculadas e a mudança na cobertura do tema ${ }^{23}$.

Este último elemento encontra-se em consonância com a opinião pública dos cidadãos brasileiros e a sua percepção acerca do PMM, além de refletir os aspectos políticos e sociais do Brasil. Alguns estudos ${ }^{24,25}$ salientam que a partir do momento em que os resultados de pesquisas de opinião popular mostraram-se a favor do PMM, os veículos de comunicação deixaram de lado as constantes declarações oficiais das entidades médicas e passaram a dar destaque aos impactos do programa, bem como a diminuir a quantidade de publicações sobre o mesmo, demonstrando a influência e o valor das opiniões dos cidadãos e do contexto político nas nuances das reportagens apresentadas. Nesse sentido, ao se tratar do contexto político brasileiro, nos últimos cinco anos, é notória a importância da queda do poder da então presidente da República, Dilma Rousseff, em 31 de agosto de 2016.

Após o declínio de Dilma Rousseff, o vice-presidente da república, Michel Temer, assumiu o poder. Ao longo de seus primeiros meses de gestão inúmeras mudanças foram propostas como a Reforma da Previdência Social, a Proposta de Emenda da Constituição (PEC) 241, que previa a limitação do crescimento das despesas do governo, a Reforma do Ensino Médio, dentre outras.

No campo da saúde destacou-se a manutenção do PMM, com algumas mudanças no seu 
financiamento, ampliação do incentivo à participação de médicos brasileiros e a suspensão de editais para a abertura de novas vagas em cursos de medicina. Destarte, o presente artigo busca identificar e analisar as repercussões na mídia brasileira acerca do PMM após o impeachment ocorrido em 2016.

\section{Método}

A pesquisa caracteriza-se por ser um estudo exploratório de caráter qualitativo, que utilizou como fonte de dados reportagens publicadas em jornais brasileiros. Os referidos jornais foram selecionados levando-se em consideração o seu grau de circulação a nível nacional e o número de tiragem diária, de acordo com o Instituto Verificador de Circulação (IVC), para o ano 2017. Foram escolhidos os três jornais com maior circulação no país. É importante destacar que apesar do jornal Super Notícia, de Minas Gerais, ser o terceiro maior jornal em circulação no Brasil, a inviabilidade de se realizar a busca online das notícias no período selecionado, bem como o seu caráter sensacionalista ${ }^{24}$, motivaram a sua substituição pelo jornal O Estado de São Paulo (Estadão), quarto maior jornal de circulação no país.

No processo de coleta de dados, buscou-se no sítio virtual dos jornais Folha de São Paulo, Estadão e $O$ Globo, por meio dos descritores "Mais Médicos" e "Programa Mais Médicos", notícias referentes ao PMM publicadas entre 31 de Agosto de 2016 (data do impeachment de Dilma Rousseff) e 20 de Junho de 2018. Foram selecionadas apenas reportagens ou notas em colunas, publicadas no referido período, que tratavam exclusivamente do PMM e que estivessem disponibilizadas online integralmente.

As notícias foram lidas e sistematizadas pelos pesquisadores em planilha Excel contendo a seguinte organização: jornal, data de publicação, título, tipo, endereço eletrônico para acesso e temática. A pesquisa resultou em 394 notícias. Destas, foram selecionadas 94 que se adequaram aos critérios pré-selecionados. A maior parte delas foi publicada no Estadão (48,9\%). No que se refere ao tipo de notícia, observou-se uma maior quantidade de publicações do tipo reportagem em relação as do tipo coluna. A quantidade de reportagens chega a ser três vezes maior do que as colunas, em todos os jornais. Estes dados são descritos na Tabela 1.

Ademais, o banco de dados foi preparado gerando o corpus de análise, analisado pelo pro- grama informático IRaMuTeQ, um software livre para a análise de dados textuais, ancorado no software R, que realiza, a partir da distribuição das palavras, diferentes formas de análises estatísticas sobre corpus textuais, como a frequência de aparição dos termos no corpus, a força de associação entre elas e sua relação temática ${ }^{27-29}$.

O relatório gerado pelo IRaMuTeQ classificou como relevante $80,9 \%$ do material. Para garantir a estabilidade dos resultados, é aceitável a classificação de, pelo menos, $70 \%$ das unidades de texto. O processo de agrupamento de palavras será apresentado na nuvem de palavras e por análise de similitude, através das quais agrupou-se e organizou-se as mesmas graficamente em função da sua frequência, possibilitando a identificação das palavras-chave do corpus e a ligação entre elas ${ }^{27-29}$.

\section{Resultados}

\section{Temporalidade}

As notícias foram publicadas principalmente no ano de 2017, nos meses de Abril (12 publicações), Agosto (09 publicações) e Novembro (08 publicações). No ano de 2018, as publicações se deram principalmente nos meses de Abril e Maio, com 09 e 05 notícias, respectivamente. A menor quantidade de publicações ocorreu em 2016, sendo realizada principalmente nos meses de Setembro e Outubro, com 06 publicações em cada mês.

Os resultados encontrados demonstram que a maior quantidade de notícias, observadas nos meses de 2017, estão associadas a eventos como a suspensão do envio de médicos pelo governo cubano; a abertura de novas vagas de graduação em medicina; e o julgamento da legalidade do PMM pelo Superior Tribunal Federal (STF). Em 2018, os eventos que afetaram a quantidade de notícias sobre o PMM foram a suspensão de editais de chamamento para a abertura de novos cursos de medicina no país e a proposta de exame de ordem para os médicos brasileiros.

Já que no que se refere ao ano de 2016, uma maior quantidade de publicações foi observada em decorrência da prorrogação do PMM e a votação da Proposta de Emenda Constitucional 241, que propunha um novo Regime Fiscal para o país com um "teto de gastos" para os serviços públicos. A distribuição das notícias selecionadas por mês e ano é apresentada no Gráfico 1, bem como os possíveis eventos que estimularam o seu crescimento. 
Tabela 1. Frequência das notícias sobre o PMM segundo o jornal no período de 31/08/2016 a 20/06/2018.

\begin{tabular}{lcll}
\hline \multicolumn{2}{ll}{ Notícias selecionadas por jornal } & \multicolumn{2}{l}{ Tipo de Notícias } \\
\hline Estadão & $46(48,9 \%)$ & Coluna & 11 \\
& & Reportagem & 35 \\
Folha de São Paulo & $32(34,8 \%)$ & Coluna & 5 \\
& & Reportagem & 27 \\
O Globo & \multirow{2}{*}{$16(16,3 \%)$} & Coluna & 4 \\
& & Reportagem & 12 \\
\hline
\end{tabular}

zes, com uma frequência média de ocorrência de $8,38 \%$ por palavra e $55,77 \%$ por segmento de texto. Nesse sentido, serão apresentadas as relações das palavras que emergiram das notícias e que foram agrupadas em função da sua frequência, com a representação na nuvem de palavras, possibilitando a identificação das palavras-chave do $\operatorname{corpus}^{18}$ (Figura 1). A análise dos dados foi realizada conjuntamente, sendo apresentada adiante.

O conteúdo das publicações selecionadas fez referência, em sua maioria, aos termos Médico (868 aparições), Saúde (348), Cubano (342), Programa (319) e Governo (248), em consonância com as principais temáticas abordadas no escopo da notícia. Tal constatação também foi observada por outros estudos ${ }^{24,26}$ que identificaram como lexemas nominais mais frequentes termos idênticos ou semelhantes.

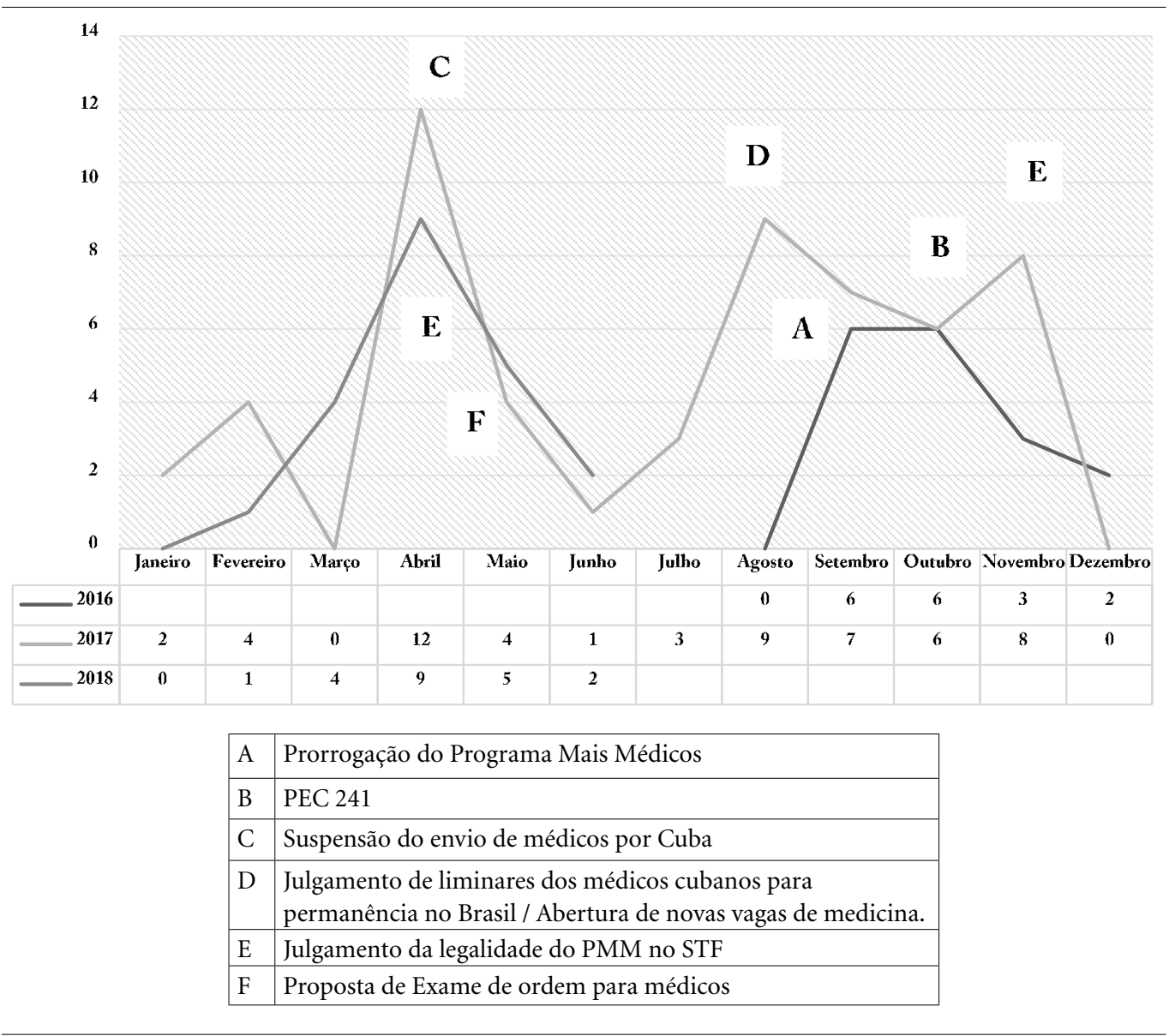

Gráfico 1. Frequência mensal de notícias sobre o PMM, no período de 31/08/2016 a 20/06/2018. 


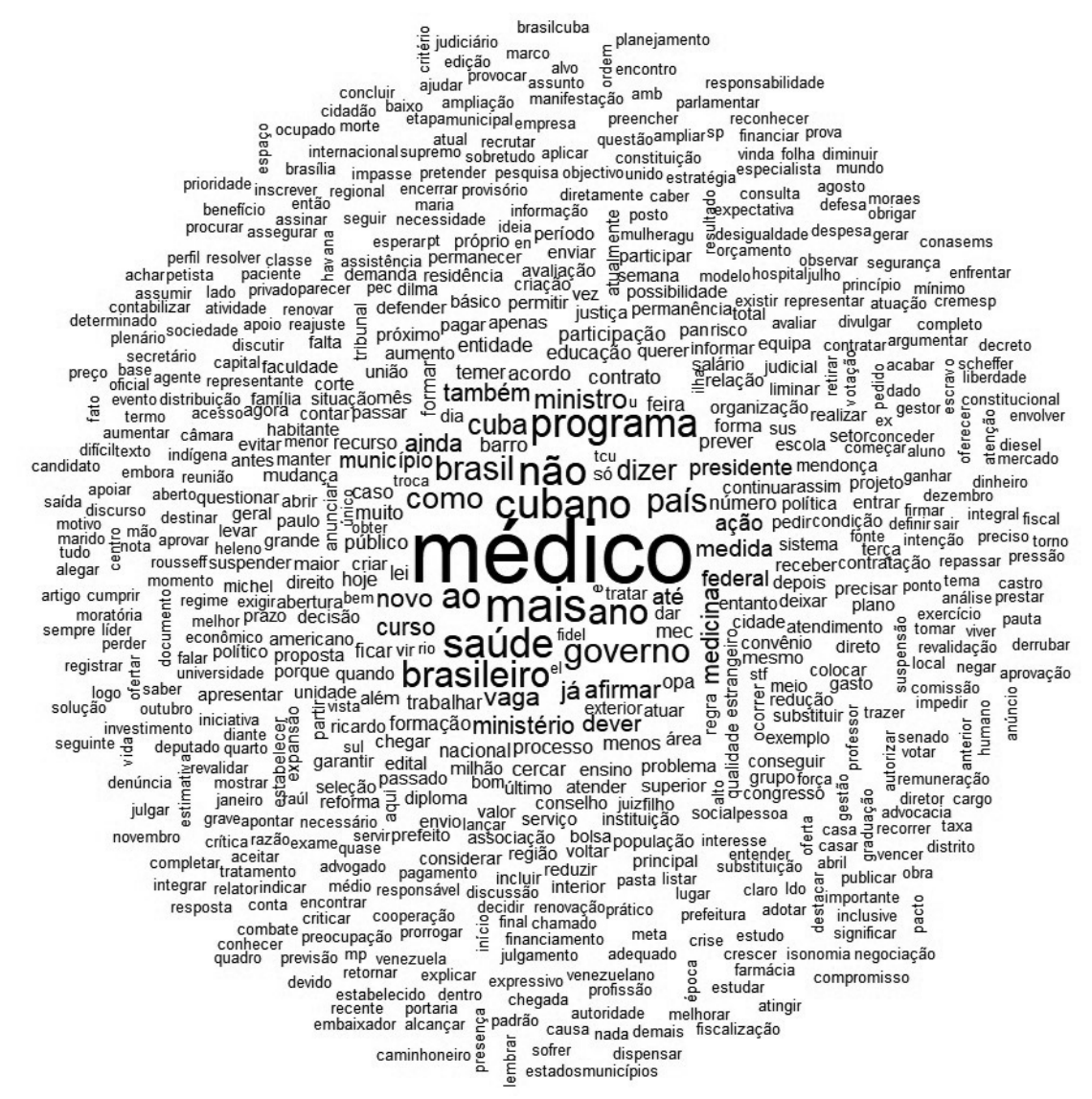

Figura 1. Nuvem de palavras sobre o PMM nas notícias de jornais.

Dando seguimento, a Figura 2 apresenta os resultados através da árvore gerada pela análise de similitude, com a identificação das concorrências entre as palavras e as indicações da conexidade entre os termos, que possuem diferentes níveis de associação entre si, a qual está diretamente relacionada à quantidade de vezes em que os termos aparecem relacionados no contexto da notícia ${ }^{27}$. O nível de associação entre os termos é representado pela largura da linha que os liga: quanto maior for a associação, maior será a largura.

Esta análise permite inferir, por exemplo, uma forte relação entre os termos: 1- médico, governo, querer e abertura; 2 - médico, governo, medicina, curso; 3 - médico, brasileiro, cubano, ficar, vaga e justiça. Tais associações estão em consonância com as principais temáticas e assuntos abordados nas notícias: abertura de novas vagas de medicina, entrada na justiça dos médi- cos cubanos para a permanência no Brasil, e as diferentes decisões do novo governo em relação ao PMM, seja em querer estimular a ampliação do número dos profissionais brasileiros participantes ou mesmo em abrir/proibir a abertura de novas vagas para medicina.

\section{Discussão}

A quantidade do fluxo de notícias publicadas está intrinsecamente relacionada aos acontecimentos de determinados eventos sociais e políticos, que podem afetar de forma direta ou indireta o PMM. Em seu estudo, Luz et al. ${ }^{24}$ notaram uma maior quantidade de publicações, no jornal Folha de São Paulo sobre o PMM, após a adoção da Medida Provisória 621, no início da chegada dos médicos cubanos e na sanção da Lei 12/871, bem 


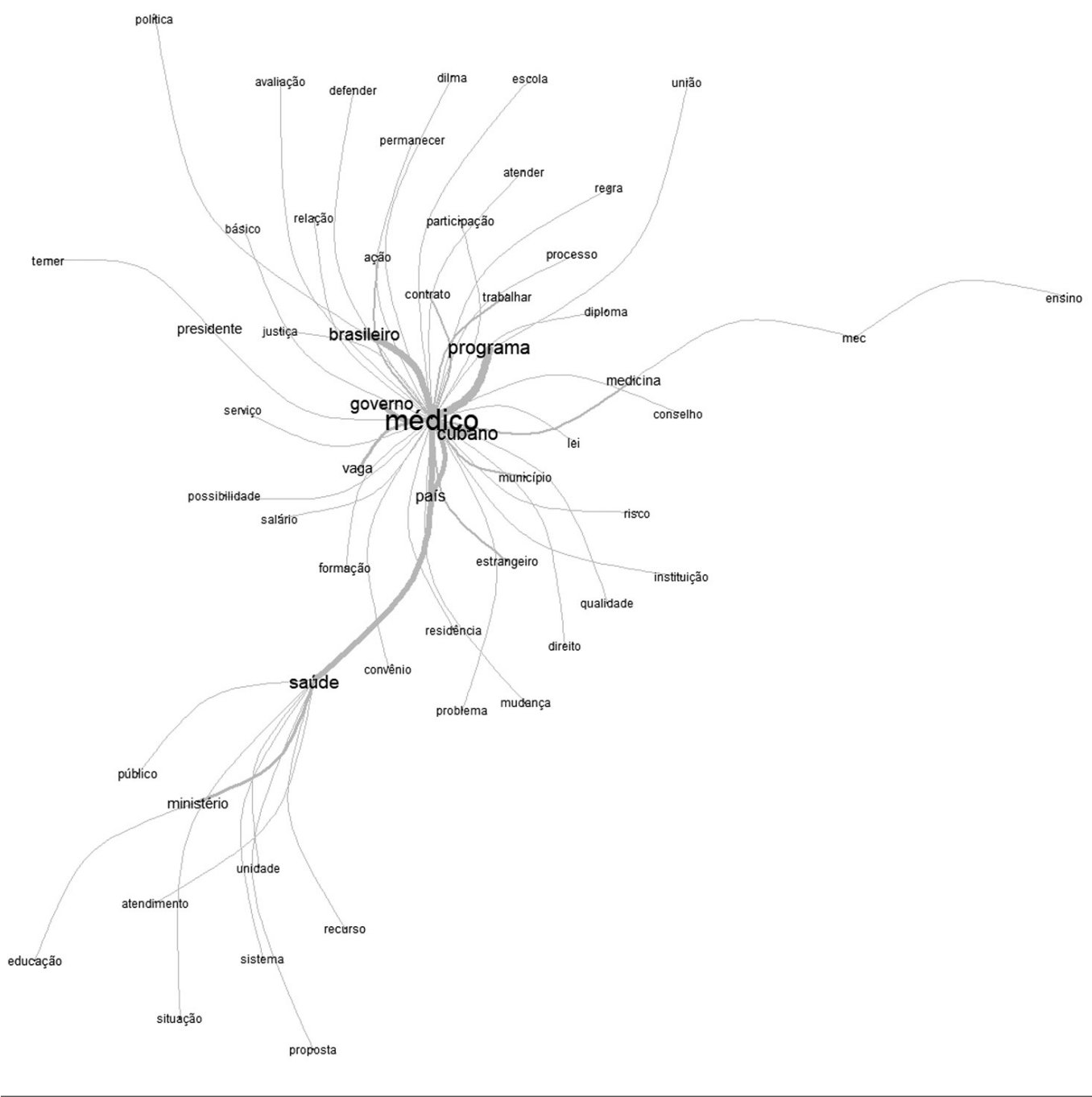

Figura 2. Árvore de elementos referentes às notícias acerca do PMM (2016-2018).

como nas publicações dos resultados das pesquisas de opiniões sobre o programa e no início da deserção dos médicos participantes.

A partir da análise, percebe-se que o termo Médico está relacionado, principalmente, com publicações referentes ao crescimento do número de médicos no Brasil e sua distribuição no país. Salienta-se, entretanto, que apesar de haver um crescimento importante na relação do número de médicos por 1000 habitantes, o Brasil ainda possui valores significativamente menores que o de outros países ${ }^{6,7}$.

Estudos que avaliam a implementação do PMM indicam esses mesmos resultados, destacando que a relação médico/habitantes cresceu em diferentes localidades do país, bem como houve uma redução significativa da carência destes profissionais em regiões tradicionalmente excluídas após a implementação do programa ${ }^{30-33}$. Outro aspecto destacado foi a expansão da cobertura da atenção básica com equidade em todas as regiões do país. Segundo Pinto et al. ${ }^{34}$, após o PMM houve um crescimento médio anual da expansão quatro vezes maior que o dos cinco anos anteriores, fazendo do programa uma das maiores iniciativas, a nível mundial, no que se refere ao provimento e distribuição de profissionais ${ }^{34}$.

O termo Saúde trata da educação médica e apresentou reportagens que versavam principalmente sobre a abertura dos novos cursos de gra- 
duação em medicina no país, questionamentos a respeito da possibilidade de fraudes na seleção da sede dos novos cursos, bem como acerca da necessidade de criação de um sistema de avaliação nacional para os futuros profissionais médicos, que atuarão sobre a saúde da população. A partir de 2018, as notícias enfocaram principalmente às discussões sobre a suspensão da abertura de novos cursos de medicina durante os próximos 05 anos.

O tema da abertura de novos cursos de medicina, principalmente no interior do país, já estava no cerne das discussões entre governo, entidades médicas e pesquisadores, que apontavam a importância de se prezar pela qualidade em vez da quantidade, acompanhando a formulação dos currículos nas novas instituições, infraestrutura e, principalmente, capacidade técnica do corpo docente ${ }^{35-37}$.

Com as previsões de aberturas de novos cursos de medicina através do PMM, o Brasil será um dos países com o maior número de escolas médicas, sendo superado apenas pela Índia, e esse crescimento dá-se principalmente em instituições privadas. Ademais, pesquisadores como Lopes $^{38}$, por exemplo, enfatizam que as vagas estão sendo criadas em municípios que não possuem a capacidade de oferecer cinco leitos por aluno nem hospital habilitado, afetando significativamente a formação dos futuros profissionais e a qualidade dos serviços que serão prestados ${ }^{38}$.

Destarte, levando-se em consideração os pleitos das entidades médicas, apoiadoras do impeachment ${ }^{20}$, e afirmando zelar pela qualidade da formação e da atenção prestada à população no que tange à sua saúde, o governo federal suspendeu os editais de chamamento público para a abertura de novos cursos, modificando, portanto, um dos principais pilares do programa.

É importante destacar que outro aspecto referente às estratégias adotadas pelo PMM, em relação à educação médica, é completamente negligenciado pelas reportagens/colunas analisadas: o tema das residências médicas, apesar de se observar na literatura científica uma maior produção em relação a este tema ${ }^{15-18}$.

A alusão ao termo Médicos cubanos englobou principalmente informações acerca da suspensão do envio de médicos pelo governo de Cuba, após o crescimento das ações de permanência impetradas pelos participantes da cooperação no Brasil; a intensa negociação do governo brasileiro com o cubano para a manutenção do envio de profissionais; o reajuste do salário destes profissionais, bem como a percepção dos cubanos acerca do programa, percepção esta muitas vezes contraditória, visto que se alguns enfatizam uma condição quase escrava ${ }^{39}$ de trabalho, outros se negavam a retornar ao seu país de origem.

A abordagem concedida aos cubanos nas notícias selecionadas ganha contornos diferentes daqueles apresentados em estudos semelhantes, que também analisaram as repercussões da mídia acerca do $\mathrm{PMM}^{26,40-42}$.

Apesar dos cubanos se manterem como um dos temas mais abordados pela mídia, eles são demonstrados com menor passividade, ocupam os espaços dos meios de comunicação para relatarem o seu cotidiano, as condições de trabalho, os laços familiares que construíram no país, bem como para criticarem o PMM e questionarem os seus direitos. Logo, os cubanos deixam de ser retratados como vítimas de xenofobias ${ }^{26,43}$, para serem mostrados como indivíduos atuantes e críticos.

O foco das notícias referentes aos cubanos também mudou, deixando de tratar das críticas dos médicos e entidades médicas para relacionar-se com processos judiciários, principalmente pela garantia da permanência no Brasil e da igualdade de salários com os médicos brasileiros. Tal situação levou o governo cubano a cancelar o envio de novos médicos ao país, gerando intensa negociação por parte do governo brasileiro para a sua manutenção, apesar da pretensão em reduzir significativamente o número de médicos estrangeiros no PMM.

As principais mudanças noticiadas acerca do PMM destacaram a prorrogação do programa pelo presidente Michel Temer; a alteração na proporção de médicos brasileiros participantes do programa, representando $44 \%$ dos profissionais, e a ampliação da concorrência entre os médicos brasileiros interessados em participar do programa, chegando a alcançar a relação de 10 candidatos para 1 vaga nos últimos 2 anos.

A mudança na proporção de médicos brasileiros participantes do programa certamente é um tema que suscita importantes discussões, visto que se no início os médicos brasileiros e as entidades médicas se opunham ao $\mathrm{PMM}^{20}$, nos últimos anos estes têm sido os principais profissionais participantes. É relevante ressaltar que desde a sua criação, o PMM propõe que os médicos brasileiros tenham prioridade na estratégia de provimento. Os profissionais estrangeiros eram alocados de forma individual ou por meio de cooperação com Cuba para locais nos quais não tinha havido preenchimento das vagas por médicos formados no Brasil ou com diploma revalidado no país ${ }^{8}$.

Tal mudança dá-se, em grande parte, em decorrência das revisões requeridas no programa 
pelo Ministério da Saúde, como a redução da contratação de médicos estrangeiros; ampliação do número de vagas para brasileiros; redistribuição da quantidade de vagas no território; cancelamento do Programa de Valorização do Profissional da Atenção Básica (Provab) e, consequentemente, da pontuação extra de $10 \%$ na residência médica, que atraia jovens profissionais, bem como a solicitação para a formulação de multas a médicos que se inscreviam no programa e abandonavam a iniciativa antes do prazo estipulado.

É importante destacar que avaliações iniciais do PMM tinham mostrado uma grande satisfação dos usuários e gestores acerca dos serviços prestados pelos médicos estrangeiros. Alguns estudos ${ }^{34,44}$ chegaram a demonstrar que os usuários consideravam, inclusive, o atendimento prestado por profissionais cubanos como qualitativamente superior ao desenvolvido pelos seus pares brasileiros, destacando como principal diferencial o olhar, a escuta, a atenção e o respeito ${ }^{44}$.

Ademais, a atuação de profissionais estrangeiros, principalmente cubanos, propiciava uma prática médica mais integrativa, que valorizava as vivências e as tradições da população, distanciando-se de ações puramente biomédicas ${ }^{45}$. Destarte, a mudança na proporção dos participantes no PMM requer o desenvolvimento de investigações que analisem a atuação desses novos profissionais e de suas práticas, além da percepção dos usuários.

O financiamento também foi um dos principais temas destacados pelos jornais acerca do PMM. As notícias versaram acerca dos possíveis riscos para a manutenção do programa, como foi o caso da aprovação da PEC 241. No primeiro semestre de 2018, as reportagens analisaram a redução do financiamento, por parte do governo federal, de programas sociais e do setor saúde, como o PMM, para subsidiar o preço do diesel, em decorrência da greve dos caminhoneiros, que além de gerar instabilidade social e redução dos níveis de aprovação do governo, propiciaram importantes impactos econômicos ${ }^{46}$.

Outro aspecto relacionado à governabilidade do programa, e tratado amplamente pela mídia foi a legalidade do PMM, após o julgamento pelo STF. Tal tema foi objeto de análise de diferentes estudos, nos primórdios do programa, principalmente no que se referia à contratação de médicos estrangeiros, a não exigência de revalidação do diploma para a atuação profissional e o recebimento, por parte destes, de salários inferiores aos dos médicos brasileiros ${ }^{47-51}$. Silva e Santos ${ }^{49}$, ao analisarem as Ações Diretas de Inconstitucionali- dade acerca do PMM, concluíram que tal política não viola preceitos constitucionais, apresentando-se como instrumento de eficácia social ao direito à saúde para as regiões prioritárias atendidas. Tal visão também foi defendida pela maioria dos ministros do Superior Tribunal Federal, que confirmaram a legitimidade do programa.

Destaca-se, ainda, as percepções dos gestores em relação ao PMM como um dos principais elementos para a sua manutenção. Esses atores, ao avaliarem positivamente o programa, destacam os seguintes pontos: a presença constante de médicos nas unidades de saúde; o cumprimento efetivo da carga horária estabelecida; a ampliação do acesso aos serviços para a população; e o aumento do número de consultas ofertadas ${ }^{52}$.

\section{Conclusões}

As repercussões na mídia acerca do PMM, após o impeachment e a mudança de governo, trataram de novas temáticas e discussões: a suspensão da abertura de novas vagas de medicina, mudança na proporção da origem dos profissionais participantes e redução do financiamento destinado ao programa. Alguns outros temas relevantes no PMM foram negligenciados, a exemplo das residências médicas. Ademais, os principais atores, que estavam no centro das discussões acerca do PMM, quais sejam, médicos brasileiros, médicos estrangeiros, entidades médicas e governo, ganharam novos contornos, apresentaram opiniões distintas das ideias defendidas no começo do programa e, muitas vezes, defenderam posicionamentos contraditórios.

Essas transformações foram noticiadas pelos jornais, que deram mais espaços para os cubanos, por exemplo, expressarem suas percepções sobre o PMM. Temas relacionados à governabilidade, educação médica e, principalmente, ao financiamento do programa assumiram o centro das discussões que antes era ocupada pelas tensões entre entidades médicas e governo.

As notícias selecionadas evidenciam que o governo, após o impeachment, apresentou posicionamento diferente em relação às entidades médicas, com aumento do diálogo e até a tomada de decisões que favoreciam as mesmas, como suspensão do chamamento público para a abertura de novas vagas em medicina pelos próximos cinco anos.

Deste modo, apesar da implementação do PMM já estar bem avançada, possuir o apoio e o respaldo popular e dos gestores municipais, mu- 
danças importantes estão sendo feitas após o impeachment e requerem uma avaliação minuciosa visando à garantia dos direitos já conquistados. Nesse sentido, a mídia pode se mostrar como um importante marcador das mudanças na sociedade.

Apesar de o estudo ter apresentado resultados importantes, se faz necessário destacar suas limitações. A primeira delas diz respeito às fontes de dados, que podem estar sujeitas à influência da lógica dos mercados culturais e midiáticos, podendo priorizar, portanto, um determinado tema em decorrência de suas aproximações ideológicas ou do perfil de seus consumidores, ao mesmo tempo em que negligenciam outros assuntos. Tal aspecto pode, assim, enviesar a frequência de determinados temas. No entanto, é importante salientar que a utilização de três distintos jornais, com visões editoriais distintas, minimiza os impactos deste aspecto.

A segunda limitação deste estudo refere-se à escolha metodológica pelo software Iramuteq, visto que o número de artigos, na área da saúde, que os utiliza ainda é ínfimo, principalmente quando se trata da apresentação dos resultados por meio das nuvens de palavras e da análise de similitude. Entretanto, é pertinente destacar que apesar dessa questão, o software possibilita a elaboração de análises e resultados com amplo rigor científico, sem interferência do pesquisador e vem sendo amplamente utilizado na literatura científica internacional, principalmente na área das ciências humanas e sociais.

\section{Colaboradores}

DRS Rios e SPC Silva participaram ativamente em todas as etapas da produção do manuscrito. Nesse particular, os mesmos trabalharam na discussão dos resultados, na redação e produção das tabelas e também, todos participaram da revisão para elaboração da versão final. 


\section{Referências}

1. Rios RDS. Mapeamento da Produção científica sobre o Programa Mais Médicos (2013-2016):contribuição ao debate sobre a atenção à saúde no SUS [monografia]. Salvador: Universidade Federal da Bahia; 2017.

2. Maciel Filho R, Branco MAF. Rumo ao Interior: médicos, saúde da família e mercado de trabalho. Rio de Janeiro: Editora Fiocruz; 2008.

3. Machado MH, Medici AC, Nogueira RP, Girardi SN. O Mercado de Trabalho em Saúde no Brasil: estrutura e conjuntura. Rio de Janeiro: Escola Nacional de Saúde Pública; 1992.

4. Machado MH. Os Médicos no Brasil: um retrato da realidade. Rio de Janeiro: Editora Fiocruz; 1997.

5. Dal Poz MR, Varela TC. Estudo de condições de formação e exercício profissional em saúde no Brasil. In: Organização Pan-Americana da Saúde, Organização Mundial da Saúde (OPAS, OMS). Recursos Humanos em Saúde no Mercosul. Rio de Janeiro: Fiocruz; 1995. p. 75-106.

6. Scheffer M, Cassenote A, Guilloux AGA, Biancarelli A, Miotto BA, Mainardi GM. Demografia Médica no Brasil 2018. São Paulo: FMUSP, CFM, Cremesp; 2018.

7. Brasil. Presidência da República. Casa Civil. Subchefia de Assuntos Jurídicos. Exposição de Motivos EMI no 00024/2013 MS MEC MP. Projeto de Medida Provisória que institui o Programa Mais Médicos. Brasília; 2013. Anexo da Medida Provisória n ${ }^{\circ} 621$, de 8 de julho de 2013.

8. Brasil. EMI no 24/2013 MS MEC MP. Medida Provisória no 621, de 8 de Julho de 2013. Diário Oficial da União 2013; 9 jul.

9. Magno LD, Paim JS. Dos clamores das ruas aos rumores no Congresso: uma análise da conjuntura recente da saúde no Brasil. RECIIS - Rev Eletron de Comun Inf Inov Saúde. 2015; 9(4):1-14.

10. Bringel B, Pleyers G. Les mobilisations de juin 2013. Paris: Éditions de la Maison des sciences de l'homme; 2013.

11. Leia o pronunciamento de Dilma Roussef sobre os protestos pelo Brasil. Folha de São Paulo. 2013 Jun 21. [acessado 2018 Jul 19]. Disponível em: http://politica. estadao.com.br/noticias/geral,leia-o-pronunciamento-de-dilma-roussefsobre-os-protestos-pelo-brasil, 1045435

12. Brasil. Lei no 12.871 , de 22 de outubro de 2013. Institui o Programa Mais Médicos, altera as Leis no 8.745 de 9 de dezembro de 1993, e no 6.932, de 7 de julho de 1981, e dá outras providências. Diário Oficial da União 2013; 22 out.

13. Brasil. Ministério da Saúde (MS). Programa mais médicos - dois anos: mais saúde para os brasileiros. Brasília: MS; 2015.

14. Alesio MM, Sousa, MF. Regulação da formação de especialistas: inter-relações com o Programa Mais Médico. Physis 2016; 26(2):633-667.

15. Ferreira NM, Cunha GT, Dias NG. O desafio da mudança: a transformação curricular de um Programa de Residência de Medicina de Família e Comunidade. Rev Bras Med Fam Comunidade 2018; 13(40):1-12.
16. Campos GWS, Pereira NJ. A Atenção Primária e o Programa Mais Médicos do Sistema Único de Saúde: conquistas e limites. Cien Saude Colet 2016; 21(1):2655-2663.

17. Silva AGS, Andrade HS. Formação Médica no Programa Mais Médicos: alguns riscos. Cien Saude Colet 2016; 21(1):2670-2671.

18. Storti MMT, Oliveira FP, Xavier AL. A expansão de vagas de residência de Medicina de Família e Comunidade por municípios e o Programa Mais Médicos. Interface (Botucatu) 2017; 21(1):1301-1314.

19. Brasil. Secretária de Educação Superior. Resolução no 2 de 2015. Adequa a legislação da Comissão Nacional de Residência Médica ao art. 22 da Lei 12.871/2013, acerca do processo de seleção pública dos candidatos aos Programas de Residência Médica. Diário Oficial da União 2015; 28 ago.

20. Soares CLM, Freitas MS, Teixeira CF, Paim JS. Análise do Posicionamento das Entidades Médicas - 20152016. Saúde em Debate 2017; 41(1):74-86.

21. Faria MA, Rocha CMF, Brites LS, Machado AMG, Santos CAR, Cechinel NFR, Nativi RSR. Programa Mais Médicos e sua repercussão na mídia: o que informar e para quem? RECIIS - Rev Eletron de Comun Inf Inov Saúde 2018; 12(1):14-25.

22. Silva VO, Rios DRS, Soares CLM, Pinto ICM, Teixeira CF. O Programa Mais Médicos: controvérsias na mídia. Saúde em Debate 2018; 42(1):489-502.

23. Paula DMP, Duarte NIG, Faria MA, Almeida JDL, Mello VRC, Rocha CMF. O Programa "Mais Médicos" na Mídia Brasileira: estado da arte. Observatório 2017; 11(1):1-13.

24. Luz CA, Cambraia CN, Gontijo ED. Monitoramento de terminologia na mídia: o Programa Mais Médicos. Tradterm 2015; 25(1):199-233.

25. Carvalho FC. A Consolidação do Programa Mais Médicos na Opinião Pública e na Cobertura Jornalística. Comunicação Guerra \& Paz 2014; 15(1):1-15.

26. Morais I, Alkmin D, Lopes J, Santos M, Leonel M, Santos R, Rosa W, Mendonça A, Sousa M. Jornais Folha de São Paulo e Correio Braziliense: o que dizem sobre o programa Mais Médicos? Rev Esc Enferm USP 2014; 48(1):107-115.

27. Camargo BV, Justo AM. IRAMUTEQ: um software gratuito para análise de dados textuais. Temas em Psicologia 2013; 21(2):513-518.

28. Ramos MG, Lima VMR, Rosa MPA. Contribuições do software IRAMUTEQ para a Análise Textual Discursiva. Ludomedia 2018; 1(1):505-514.

29. Kami MTM, Larocca LM, Chaves MMN, Lowen IMV Souza VMP, Goto DYN. Working in the street clinic: use of IRAMUTEQ software on the support of qualitative research. Escola Anna Nery 2016; 20(1):1-5.

30. Vanzella E. Proporção de Médicos em Relação a População: Um modelo matemático para estimação. Revista Eletrônica Estácio Saúde 2014; 3(1):42-54.

31. Alencar APA, Xavier SPL, Laurentino PAS, Li PF, Nascimento VB, Carneiro N, Fonseca A, Fonseca FLA. Impacto do programa mais médicos na atenção básica de um município do sertão central nordestino. Revista de Educação, Gestão e Sociedade 2016; 26(10):1290-1301. 
32. Mota RG, Barros NF. O Programa Mais Médicos no Estado de Mato Grosso, Brasil: uma análise de implementação. Cien Saude Colet 2016; 21(9):879-288.

33. Silva BP, Stockmann D, Lúcio DS, Henna E, Rocha MCP, Junqueira FM. Ampliação do acesso à saúde na região mais vulnerável do estado de São Paulo, Brasil: reflexo do Programa Mais Médicos? Cien Saude Colet 2016; 21(9):2899-2906.

34. Pinto HA, Oliveira FP, Santana JSS, Santos FOS, Araújo SQ, Figueiredo AM. Programa Mais Médicos: avaliando a implantação do Eixo Provimento de 2013 a 2015. Interface (Botucatu) 2017; 21(1):1087-1101.

35. Silva Junior AG, Andrade HS. Formação Médica no Programa Mais Médicos: alguns riscos. Cien Saude Colet 2016; 21(9):2670-2671.

36. Amaral JLG. Mais médicos: melhor atenção à saúde da população? Sao Paulo Med J 2013; 130(3):139-140.

37. Schanaider A. Mais ou menos médicos! Revista do Colégio Brasileiro de Cirurgiões 2014; 41(5):303-304.

38. Lopes AC. A explosão numérica das escolas médicas brasileiras. Educación Médica 2018; 19(1):19-24.

39. Médicos cubanos reclamam de 'escravidão' em trabalho no Brasil. Jornal Folha de São Paulo; 2017 Set 29; p. 10.

40. Segalin M. O Program MM: um estudo de imagem a partir da revista veja [monografia]. Porto Alegre: Universidade Federal do Rio Grande do Sul; 2013.

41. Scremin L, Javorski E. O enquadramento das notícias sobre os estrangeiros no programa mais médicos. Anais do IX Ciclo de Debates Sobre Jornalismo da UniBrasil. Paraná; 2013

42. Souza L. Representação do programa MM pelo site do pragmatismo político e pelo portal do conselho federal de medicina [dissertação]. Brasília: Universidade de Brasília; 2014.

43. Camurça LI. Um estudo sobre a relação entre a Democracia Digital e a Participação Política a partir do debate sobre o Programa Mais Médicos no Facebook. Revista Eletrônica do Programa de Pós-graduação em Mídia e cotidiano 2014; 3(2):538-561.

44. Silva IEP. Tem hora que a gente se pergunta por que é que não se junta tudo numa coisa só?: programa mais médicos para o Brasil: caminhos da intersetorialidade. [monografia]. Porto Alegre: Universidade Federal do Rio Grande do Sul; 2016.

45. Molina J, Suarez J, Lucimar R, Cannon C, Oliveira G, Fortunato MA. O programa Mais Médicos e as Redes de Atenção a saúde no Brasil. Saúde para Debate 2014; 52(1):190-201.
46. Para baixar diesel, governo corta verba de programas de transplantes e de combate ao trabalho escravo. $O$ Globo 2018; Maio 31. [acessado 2018 Jul 19]. Disponível em: https://oglobo.globo.com/economia/ para-baixar-diesel-governo-corta-verba-de-programas-de-transplantes-de-combate-ao-trabalho-escravo-22736291

47. Matte NA. A justiça do trabalho e o discurso normativo: a violação das garantias trabalhistas no Programa Mais Médicos para o Brasil (LEI 12.871/2013) [monografia]. Brasília: Centro Universitário de Brasília; 2015.

48. Di Jorge FM. Estudo jurídico do Programa Mais Médicos. Acta JUS 2013; 1(1):24-34.

49. Silva SM, Santos LMP. Estudo das ações diretas de inconstitucionalidade do Programa Mais Médicos. Cadernos Ibero-Americanos de Direito Sanitário 2015; 4(2):68-82.

50. Schneider Y, Oliveira J. Políticas públicas de efetivação do direito social à saúde: Programa Mais Médicos sob uma análise da ponderação de princípios. Revista da Academia Brasileira de Direito Constitucional 2015; 7(13):371-393.

51. Oliveira FJ. Contratação de estrangeiros sob a Lei federal 12.871/2013 (Projeto Mais Médicos para o Brasil). Rev. direito adm. Contemp. 2014; 2(9):59-73.

52. Organização Pan-Americana de Saúde (OPAS). Implementação do Programa "Mais Médicos" em Curitiba. Experiências inovadoras e lições aprendidas [Internet]. 2015 [citado 10 Mar 2016]. Disponível em: http://www.otics.org/estacoes-de-observacao/observatorio-mais-medicos

Artigo apresentado em 29/08/2018

Aprovado em 12/04/2019

Versão final apresentada em 14/04/2019 